\title{
The Impact of Economic Indicators on Food Supply Chain of Palestine
}

\author{
D.O.I - 10.51201/Jusst12555
}

http://doi.org/10.51201/Jusst12555

\author{
Ahmad Shwekeh ${ }^{1}$, Ahmed Zaid ${ }^{2}$, Mohammed W. A. Saleh ${ }^{3}$, Marwan \\ Mohammad Khaleel Mansour ${ }^{4}$ \\ ${ }^{1}$ Department of Computerized Financial and Banking Science, \\ PalestinianTechnical University-Kadoorie (PTUK), Tulkarm-Palestine. \\ ${ }^{2}$ Department of Industrial Management, Palestinian Technical \\ UniversityKadoorie (PTUK), Tulkarm-Palestine. \\ ${ }^{3}$ Deprtment of Accounting Information System, Palestine Technical \\ University- Khadoori \\ ${ }^{4}$ Faculty of Business, Economics and Social Development, Universiti \\ Malaysia Terengganu-Malaysia/Terengganu
}

\begin{abstract}
Food supply chain has become a crucial segment of every economy especially after the COVID-19. Lockdown was imposed in Palestine that is why it was very hard to maintain food supply chain from forms to end-users. Pandemic disturb every economy but developing economies like Palestine was more vulnerable. Although, Palestine authorities did their best by adopting best economic practices still various indicators impact the food supply chain. The aim of this article is empirically find out the impact of economic indicators on food supply chain. This is quantitative study and the questionnaire was adopted from well reputed studies. The data was collected by convenience sampling and analysed by structuring equation modelling through Smart PLS. The finding of this study revealed that inflation rate is negatively effecting the performance of food supply chain although economic indicators are not significant impacting. This study has unique findings it has been found that HDI is positively and significantly effecting food supply chain and HDI is also positively and significantly effecting the GDP but GDP is also positively impacting food supply chain but not significantly. This may be because of emerging country that heavily rely on external support and has less industrialization. This study help manages to understand that inflation is very bad for food supply chain so they must take care of inflation rate while decision making. This study help government to take necessary measures regarding interest rate and inflation rates. Next study can be conducted other parameters of economic indicators and industry to generalize the findings.
\end{abstract}

Keywords: Economic Indicators; Food Industry; Supply Chain

\section{Introduction}

A business can differentiate its products and services based on a range of different factors such as price, quality, convenience, and service. But 
differentiating by offering environmentally beneficial products i.e., technology is not only a different game but a game changer as well. This study is about to examine the performance of supply chain companies or firms in Palestine through task-technology fit, in which it explores the impact of information system compatibility, information technology and technology innovativeness on performance [1]. The research supports the concept that more consideration should be given to supply chains processes. In order to get better profit on investment, managers should focus on assigning the resources toward information technologies so that they support performance. Which helps the firm to increase its overall performance Utilization of the new raw material or goods will be less import. Proper supply chains help in to decrease carbon foot print which helps in environmental sustainability[2]. Thus, new a department enclosure will be creating new investments and employment opportunities such as more and skilled can be employed in order to benefit from their expertise. This research is helpful to create awareness amongst the supply chaining firm and motivate them to convert their normal supply chains into effective supply chains [3]. This is because the awareness about recycling and supply chains and been already created but now it's time for the implementation and bring it into action phase.

\section{Literature review}

Supply chain is that the network of organizations that square measure concerned, through upstream and downstream linkages, within the totally different processes and activities that end up worth within the variability of product and services delivered to the ultimate word client. Internal lean practices square measure the activities of eliminating waste like price and time within the supply chaining system [4]. The term lean is pertaining to a system that uses less input to supply at a mass-production speed and at constant time be ready to provide additional selection to the tip customers". Ranking manager features a better understanding of provide chain management's want as a result of they're the foremost necessary those that will acknowledge the firm's strategic imperatives to remain competitive within the market place. Open sharing of knowledge like inventory levels, forecasts, marketing ways, and selling ways reduces the uncertainty between provide partners and results in increased performance. This chapter provides a summary of this research. It describes the background and problems with the auto business and therefore the way provide chain practices and uplifts the performance through product innovation, analysis queries, objectives, important of study and organization of this research [5]. It conjointly provides some general outlook on the auto business in Asian country. The aim is to provide the reader with a fast image of the study. Within subsequent chapter, past researchers' studies are getting to be mentioned to identify a theoretical framework and potential hypotheses for this research [6].

\subsection{Food Supply Chain}

The food processing industry is considered one of the oldest industries in Palestine. In its early days, the industry was limited to producing fewer processed foods and sweets. Currently, the industry plays a major role in the Palestinian economy and its overall domestic product. In addition, the sector has created job opportunities in the domestic market [7]. The importance of 
this sector is also given to use food that is needed for food safety in Palestine where 120 different foods are prepared. According to the Palestine Food Industries Union, the most important food processing industries in the West Bank are related to the agricultural products targeted for this purpose: canned vegetables and fruits [8].

In Palestine, there are only few specialized industries that produce canned vegetables and fruits, and currently employ hundreds of workers. Investment in the industry is estimated at millions, and these products make up $20 \%$ of the total market capitalization. In addition, it contributes majorly in the total exports [9]. However, the industry still has the necessary packaging methods and warehouses, the supply of which will lead to high investment. Oils and vegetable oils. There are nine industries operating in the industry, employing many workers. Investment in the industry is in millions, and these products make up 30\% of the market [10]. Pasta and vermicelli [11].

\subsection{Economic Indicators}

Procurement performance has been closely monitored and learned academically, commercially, and economically. However, the documents are still missing from the effects of economic indicators on commercial activities, especially in the food industry. Economic indicators include; inflation rate, interest rate, human development index (FDI) and gross domestic product (GDP). The food industry is an industry that has been operating for centuries. It has recently grown rapidly and is considered an important factor in economic growth in various countries [12].China is leading the export. However, as research has focused on the Palestine food industry, food supply chain is ranked highly in the world in terms of foreign exchange. Therefore, the current study focuses on these factors to assess the effect of economic indicators on commercial performance in the food industry in Indonesia [13].

Various studies have examined the relationship between commercial activity and the food industry but no studies have officially documented the role of economic indicators in commercial performance (Hameri and Pálsson, 2003; Islam and Habib, 2013; Ogden, 2008). Therefore, the purpose of the present study is to examine the role of economic indicators in the performance of the sale of goods. Some purposes are given how economic indicators work in real estate operations [14].

\subsection{Palestinian Economy}

The Palestinian Department of Agriculture does not pay much attention to the search for and support of emerging science related to agricultural production and agricultural technology," he said. "The department relies on donors to the international community, who are unable to meet the needs of the sector, and who are disabled for work, restricting access, mobility and resources. However, since Israel and Egypt control all borders, Palestinian farmers must work within a broken purchase that reduces their competition. In February, Tubas began building a wastewater treatment plant to supply water for agricultural use, but it will not end until September 2017. Meanwhile, tight controls control the use, and Palestinians are barred from digging new sources, according to a report from the Centre for Economic Policy Research (CEPR) [15].

Most of the targeted families are headed by women, with elderly people, persons with families have been affected by the spike disabilities and high ratio of dependents. Already before the outbreak of in COVID-19 in Gaza, WFP will 
aim at providing food assistance to COVID-19, the food insecurity in Palestine affected nearly a third of the non-refugees (125,000 people). WFP needs USD 4.5 million to population - about 1.7 million people - and is driven by high poverty and provide CBTs (USD 10.3 per capita/month) to the targeted unemployment rates. The number of food-insecure Palestinians is almost affected people for 3 months [4]. Equally divided between the refugee (55\%) and non-refugee (45\%) [1]. Furthermore, WFP will aim at increasing the voucher value (USD communities. More than 700,000 non-refugees are assessed to be food 15.30 vs USD 10.30) to 123,200 people who regularly receive insecure in Palestine, 465,000 in Gaza and 235,000 in the West Bank. WFP's CBT assistance through the MoSD. Additional USD 2 million. Under 2018-22 Country Strategic Plan (CSP), WFP aims at providing food Poverty rate: 29.2 per cent are needed to provide this extra assistance for three months. Assistance to 426,000 of the most vulnerable non-refugees via in-kind food rations and electronic food vouchers. Assisted communities can redeem [3]. Most of these newly maintaining peace and stability, and stimulates the local economy [16]. WFP registered beneficiaries (99 percent) reside in the West Bank also works with national institutions to enhance the capacity of existing where the impact of job loss linked to anti-COVID-19 closures and social safety nets to assist the poor and vulnerable.

\subsection{Research framework}

Based on above literature and challenges that Palestine food industry faced this study proposed that due to current pandemic there is need to know that how much this pandemic impact the food supply chain especially in term of economic indicators. Below research framework has been adopted and hypothesis were drafted that is being tested in this study.

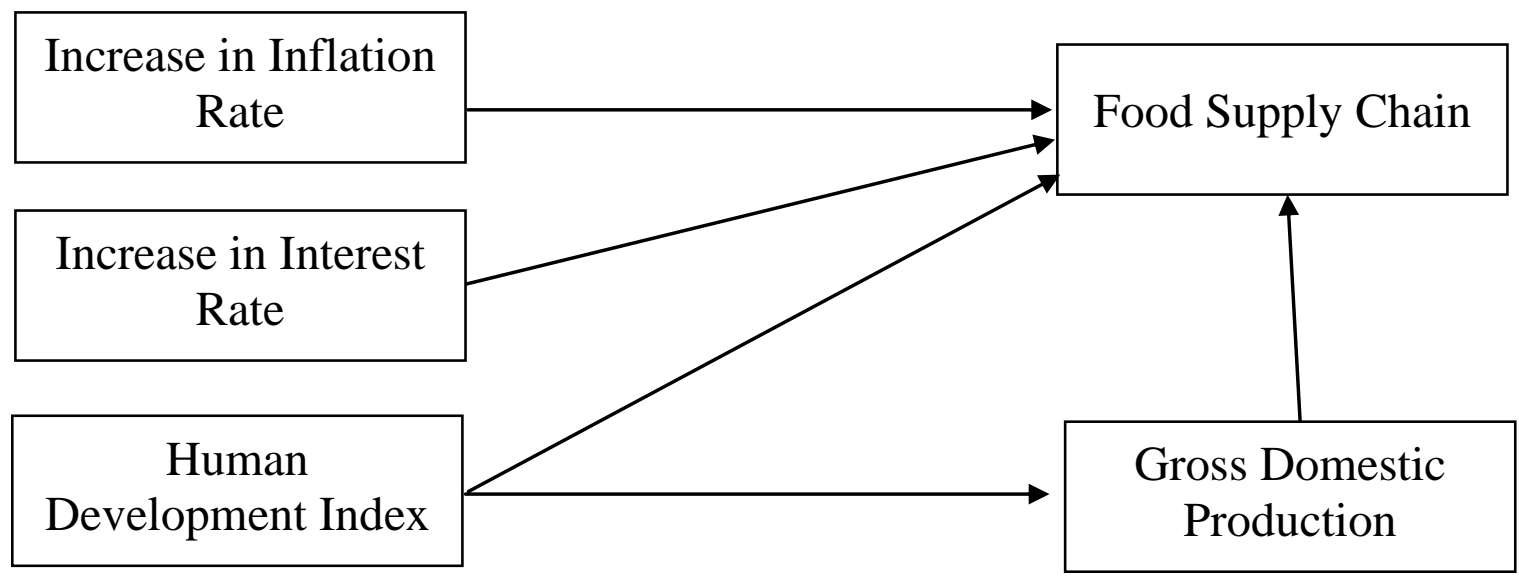

Figure 1 Research framework

Inflation is another important change in macroeconomics. Inflation is seen as a general increase within the price of an asset over a period of your time. In any case when the traditional price of products increases, the purchasing power of the buyer decreases, which features a negative effect on the performance of the products. Financial strategies are often thought to manage inflation. The financial institution uses those financial strategies to regulate economic activity to take care of and protect inflation. Inflation brings the acquisition and sale of products and services between a buyer and a seller who features a significant relationship with the acquisition of products and services. Inflation, reduces 
purchasing power [17]. The customer usually pays the worth too late as are often expected, or, in other words, could also be blocked by the vendor. Inflation destroys services and products that cause a risk to the vendor in late payment. The customer usually returns late to create up his aggregate value. Therefore, inflation alike takes value for traders and buyers of temporary goods[18]. This example drives the simplest thanks to find how to use for a sale policy for a purchase plan. Because the land industry is essentially supported the transfer of products and services, it therefore features a significant impact on inflation. Inflation raises prices that negatively affect purchasing power [12]. The stock rate changes over time thanks to losses thanks to inflation. Given the chance to be available at the time t. Stock loss occurs as a result of demand and decay. Depreciation can occur when items are available during $t$, and there's no material damage once we aren't in time because they're not always there. A model of underlying assets is shown in Figure 1. Therefore, it's proposed under hypothesis [19].

Interest rate is that the annual value charged by lenders to lenders. Typically, money establishments or lenders place interest on the recipient reckoning on the whole loan quantity. It's thought-about associate degree improvement in European bank interest rates from 2003 to 2011. The money crisis is alleged to own forced neighbouring European banks to satisfy insurance needs. At a time once the bank is that specialize in choices to deal with basic desires, European banks are handling money uncertainty. This variation within the charge per unit contains an important impact on the getting power of varied merchandise and services[20]. It's been found that interest rates ought to be stabilised to avoid unessential economic consequences. As a result of it raises the value associate degreed lowers the getting power that contains a negative impact on the performance of a quality. It had been meant to diversify interest rates within the Palestine industry from 2002 to 2011. These money establishments' area unit consultants in managing the money development of forty fourth million folks [3]. The result shows that the flexibleness (bank-based) yields a lot of complicated results compared to the varied factors (macroeconomics) with the final word goal of determinative the charge per unit unfold in African nation. Higher management of economic establishments at interest rates influences the sale of products and services. However, political influence will interfere with money matters [4]. The shopper doesn't pay interest at the time of receipt presumptuous it pays that amount; however, if the instalment is delayed and not paid on time, interest is charged. The shopper will begin grouping cash from the agreement or use of the item, and earn interest thereon financial gain. Therefore, it's to the client's advantage to permit the instalment from the supplier to expire [10].

The Human Development Index (HDI) is one among the integrated indicators of life time, individual income and education with various indicators wont to place different countries within the four stages of human development [12]. The country gets a better HDI where the extent of education is above others, anticipation is higher and GDP per capita is high. HDI is one among the key development indicators with a robust relationship to GDP and procurement performance in various firms [7]. It's considered a minority like education, income, and welfare for the aim of keeping track of which human development priorities are considered the foremost important within the world. Details of this study were taken from the planet Bank also because the HDI details of the United Nations Development Program [3]. Since transactions are hooked in to the transfer of products and services that need a particular level of skills and 
education, therefore, HDI is critical to the performance of the asset. Better education and skills that improve productivity that have a positive impact on GDP and procurement performance [1]. Like both purchasing performance and GDP there's a strong correlation with one another[21]. Therefore, it's clear that HDI plays a crucial role in improving GDP and GDP also plays a crucial role in asset performance. Therefore, the ideas below are recommended.

H1: Increase in inflation rate negatively impact the food supply chain of Palestine.

H2: Increase in interest rate negatively impact the food supply chain of Palestine.

H3: Increases in HDI positively impact the food supply chain Palestine.

H4: Increases in HDI positively impact the GDP of Palestine.

H5: Increases in GDP positively impact the food supply chain of Palestine.

H6: GDP mediates the relationship between HDI and supply chain of Palestine.

\section{Research Methodology}

In this quantitative study, the researcher performed descriptive statistics and analyses the frequency of regular reporting and quantity variability associated with human data. Social Sciences Scientific Package (SPSS). The relationship between visible and hidden variables is expressed through uploads that inform researchers about the level of a given indicator that can measure variables or functions as active coefficients. In addition, the Confirmatory feature analysis in the Statistical Package of Social Sciences (SPSS) is prepared and validated by the rating model. In this research project, a pilot test is performed prior to actual research. Pilot testing serves as a tool to help the researcher identify problems and make necessary adjustments. Key data is collected through a questionnaire and will be processed via SPSS. Final data analysis was made by structuring equation modelling through Smart PLS. It starts with analytical methods from query developing to data analysis method. The questionnaire was a survey tool of the data collection, it was developed based on a five-point Likert scale where response ranges from minimum value $1=$ Strongly Disagree to maximum value 5= Strongly Agree.

\section{Results and Discussion}

According to [22], descriptive statistics include graphical and numerical procedures that are used to summarize and process data and transform data into information. In this research study, it is used to analyse the demographic and general data. The results of a descriptive analysis can be presented using a table in the form of a bar chart. In this research project, the descriptive analysis is used to analyse the respondent's demographic information. 


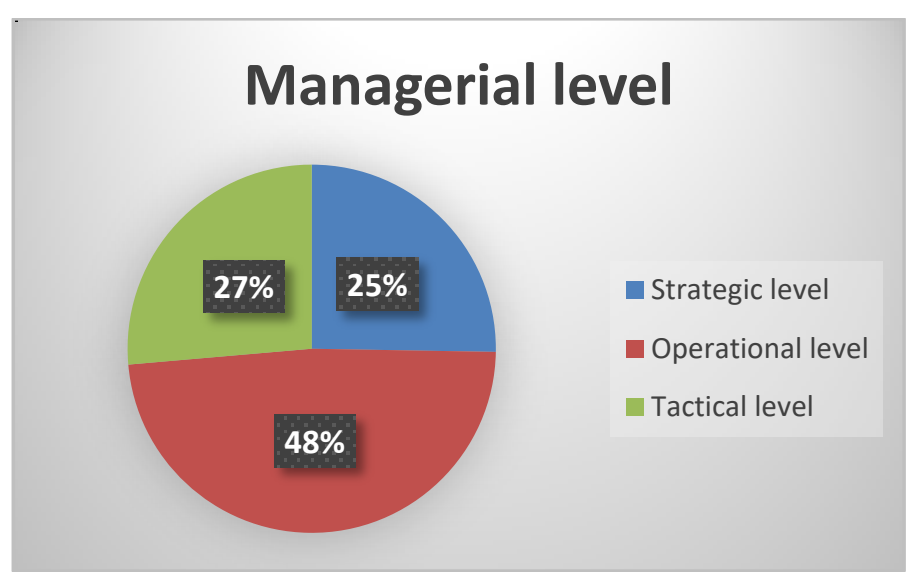

Figure 2 Managerial level of respondents

First step was data screening. This study has checked missing values, normality, linearity, outliers[23]. All the necessary measurement has been taken to clean the data before the final analysis. Secondly, below are the reliability and validity analysis.

Table 1 Reliability analysis

\begin{tabular}{|c|c|c|c|c|}
\hline & $\begin{array}{l}\text { Factor } \\
\text { loadings }\end{array}$ & $\begin{array}{l}\text { Cronbach's } \\
\text { Alpha }\end{array}$ & $\begin{array}{l}\text { Composite } \\
\text { Reliability }\end{array}$ & AVF \\
\hline${ }_{\mathrm{C} 1}{ }^{\mathrm{FS}}$ & 0.795 & \multirow{7}{*}{0.862} & \multirow{7}{*}{0.884} & \multirow{7}{*}{0.526} \\
\hline $\mathrm{C} 22^{\mathrm{FS}}$ & 0.627 & & & \\
\hline $\mathrm{C} 3^{\mathrm{FS}}$ & 0.624 & & & \\
\hline${ }_{\mathrm{C} 4} \mathrm{FS}$ & 0.717 & & & \\
\hline${ }^{2} 5^{\text {FS }}$ & 0.862 & & & \\
\hline${ }^{2} 6^{\text {FS }}$ & 0.625 & & & \\
\hline $\begin{array}{l}\text { FS } \\
\text { C7 }\end{array}$ & 0.788 & & & \\
\hline${ }_{\mathrm{P} 1}{ }^{\mathrm{GD}}$ & 0.532 & \multirow{7}{*}{0.835} & \multirow{7}{*}{0.875} & \multirow{7}{*}{0.504} \\
\hline $\mathrm{P} 2^{\mathrm{GD}}$ & 0.726 & & & \\
\hline${ }_{\mathrm{P} 3}^{\mathrm{GD}}$ & 0.846 & & & \\
\hline${ }_{\mathrm{P} 4}^{\mathrm{GD}}$ & 0.739 & & & \\
\hline${ }_{\mathrm{P} 5}^{\mathrm{GD}}$ & 0.708 & & & \\
\hline P6 ${ }^{\mathrm{GD}}$ & 0.671 & & & \\
\hline $\begin{array}{l}{ }^{2} \text { GD } \\
\text { P7 }\end{array}$ & 0.712 & & & \\
\hline HD & 0.765 & 0.867 & 0.898 & 0.595 \\
\hline
\end{tabular}




\begin{tabular}{|c|c|c|c|c|}
\hline 1 & & & & \\
\hline $\mathrm{I} 2^{\mathrm{HD}}$ & 0.795 & & & \\
\hline I3 ${ }^{\mathrm{HD}}$ & 0.775 & & & \\
\hline $\mathrm{I} 4^{\mathrm{HD}}$ & 0.812 & & & \\
\hline $\mathrm{I}^{\mathrm{HD}}$ & 0.740 & & & \\
\hline $\mathrm{I}^{\mathrm{HD}}$ & 0.736 & & & \\
\hline $1^{\text {INF }}$ & 0.599 & \multirow{6}{*}{0.822} & \multirow{6}{*}{0.868} & \multirow{6}{*}{0.524} \\
\hline $2^{\text {INF }}$ & 0.803 & & & \\
\hline $3^{\text {INF }}$ & 0.737 & & & \\
\hline $5^{\text {INF }}$ & 0.771 & & & \\
\hline $6^{\text {INF }}$ & 0.734 & & & \\
\hline $7^{\text {INF }}$ & 0.683 & & & \\
\hline $1^{\text {INT }}$ & 0.799 & \multirow{5}{*}{0.816} & \multirow{5}{*}{0.861} & \multirow{5}{*}{0.558} \\
\hline $2^{\text {INT }}$ & 0.575 & & & \\
\hline $4^{\text {INT }}$ & 0.852 & & & \\
\hline $6^{\text {INT }}$ & 0.660 & & & \\
\hline $7_{7}$ INT & 0.812 & & & \\
\hline
\end{tabular}

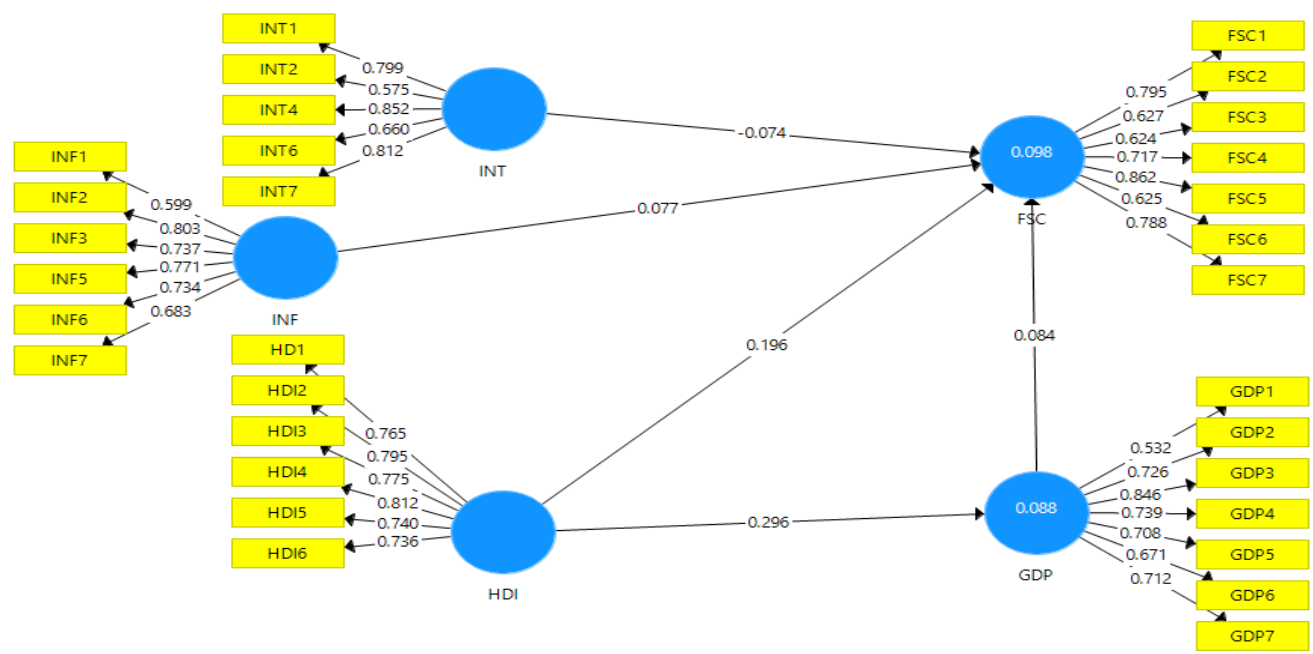

Figure 1 Measurement model 
Table 2 Discriminant Validity

\begin{tabular}{cccccc}
\hline & FSC & GDP & HDI & INF & INT \\
\hline FSC & $\mathbf{0 . 7 2 5}$ & & & & \\
GDP & 0.172 & $\mathbf{0 . 7 1 0}$ & & & \\
HDI & 0.281 & 0.296 & $\mathbf{0 . 7 7 1}$ & & \\
INF & 0.186 & 0.228 & 0.364 & $\mathbf{0 . 7 2 4}$ & \\
INT & -0.191 & -0.178 & -0.425 & -0.247 & $\mathbf{0 . 7 4 7}$ \\
\hline
\end{tabular}

This study has checked reliability and validity of the data. Table 1 , table 2 and figure 3 shows that all the values are meeting the threshold limit. Thus, it can be concluded that the instrument is valid and reliable. The range of mean value is 3.2114 to 3.7543 which shows that the response of the respondents to the questionnaire is more towards being neutral and more towards agrees. The standards deviation value above shows the deviation of response from means and value ranges from .74135 to 1.02596 which indicates that respondents have possessed the difference of opinion on the questions in the survey tool.

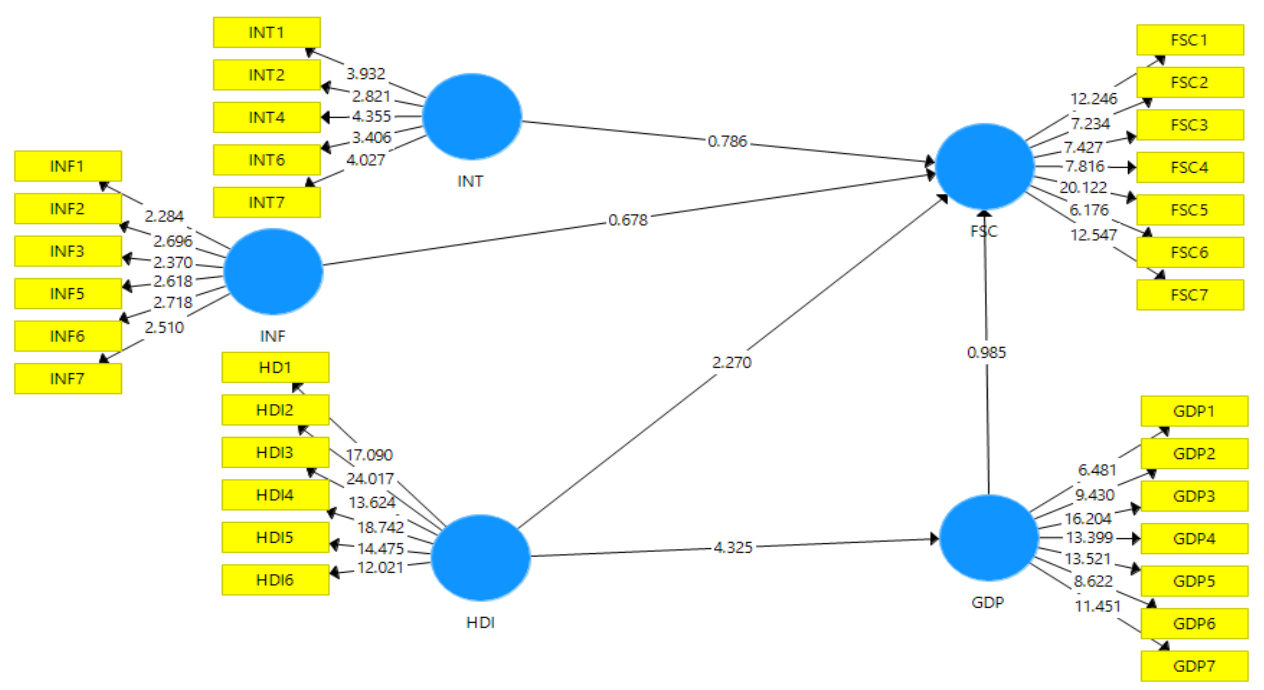

Figure 1 Structural model

Table 3 Hypothesis testing

\begin{tabular}{ccccc}
\hline Hypothesis & Relationships & Beta-Values & T-Values & Decisions \\
\hline H1 & INT $\rightarrow$ FSC & 0.074 & 0.786 & Rejected \\
H2 & INF $\rightarrow$ FSC & 0.077 & 0.678 & Rejected \\
H3 & HDI $\rightarrow$ FSC & 0.196 & 2.270 & Accepted \\
H4 & HDI $\rightarrow$ GDP & 0.296 & 4.325 & Accepted \\
H5 & GDP $\rightarrow$ FSC & 0.084 & 0.985 & Rejected \\
\hline
\end{tabular}

Table 4 Mediation analysis

\begin{tabular}{lllll}
\hline Hypothesis & Relationship & Beta - value & T - value & Result \\
\hline H6 & HDI -> GDP -> FSC & 0.025 & 0.856 & Rejected \\
\hline
\end{tabular}


The contribution of this research project is summarized below and the facts will be useful for the Palestine food supply chain regulatory authorities, food supply chain, researcher, and the reader of this project. This research is adding to the literature on the impact of supply chain practices on product innovation in food supply chain industry Palestine by investigating the facts that how leadership, supplier relationship, lean practices, quality information analysis and customer focus promotes innovation in an organization. The main supply chain factor which has been discovered in this research is the interest rate and inflation rate due to which the performance of food supply chain is profound in the organizations. Secondly, HDI focus is considered as the most significant factor since the user requirement is defined, therefore, personnel involved in the performance of industry[24]. The research has several interesting contributions for food supply chain industry officials and for the Palestine food supply chain regulatory authorities that how best supply chain practices bring innovation in the industry.

There are several limitations and recommendations for future researchers to add their contribution to literature so that the industry can be benefitted. First, the Model R square shows the value of 0.098 only this indicates that food supply chain industry is predicted by 4 independent variables (Interest rates, inflation rate, HDI, GDP) is not only contributing factor. There could be other factors that may contribute to the performance of the food supply chain industry which can be explored in the future. Some of the factors which we have observed are sustainable supply chain, green supply chain, supply chain competency, and consumer preference focus can be considered to measure the effect of innovation in the food supply chain industry.

Secondly, this research is based on the food industry only whereas the food supply chain industry consists on limited firms' future researcher may widen their scope to and consider the entire industry as their sample size to better understand the impact of supply chain performance.

\section{Conclusion}

The current research study's significance twofold; the first is from the perspective of its contribution to the existing literature. The current research study will help to evolve an understanding of the relationships between independent variables (Interest rate, inflation rates, Gross Domestic Production and Human Development Index) and dependent variable which is Food Supply Chain of Palestine. The literature has shown that no such any study has been conducted in the scenario of emerging markets such as Palestine. Therefore, the current study will help to bridge the gap in the literature. The second significance of the study is from the point of a manager; the current study will help supply chain managers working in the food supply chain industry of Palestine to formulate practical strategy.

\section{References}

L[1] O. Sinaga, M. H. M. Saudi, and D. Roespinoedji, "The relationship between economic indicators, gross domestic product (GDP) and supply chain performance," Polish J. Manag. Stud., vol. 18, no. 1, pp. 338-352, 2018, doi: 10.17512/pjms.2018.18.1.25.

[2] M. S. Shahbaz, M. A. Qureshi, S. Sohu, and M. A. Keerio, "The Impacts of Operational Risks in the Supply Chain of Construction Projects in Malaysia," Teh. Vjesn., vol. 27, no. 6, pp. 1887-1893, 2020, doi: 10.17559/TV- 
20190727192125.

[3] Y. Hakimah, S. K. Hildayanti, and A. T. Nugraha, "Influence of economic indicators on supply chain: Evidence from Indonesian fishing industry," Int. J. Supply Chain Manag., vol. 8, no. 5, pp. 854-863, 2019.

[4] M. Goransson, "Dynamically Predicted Shelf-life Service: Exploring and Evaluating a Potential Sustainable Food Supply Chain Innovation," Lund University, 2019.

[5] L. Bai, "Exploratory Study of Environmentally Sustainable Supply Chain in New Zealand Food Industry," Massey University, 2011.

[6] M. M. Aung and Y. S. Chang, "Traceability in a food supply chain: Safety and quality perspectives," Food Control, vol. 39, no. 1, pp. 172-184, 2014, doi: 10.1016/j.foodcont.2013.11.007.

[7] Word Food Program, "WFP Palestine Country Brief," 2020.

[8] A. Gunasekaran, C. Patel, and E. Tirtiroglu, "Performance measures and metrics in a supply chain environment," Int. J. Oper. Prod. Manag., vol. 21, no. 1/2, pp. 71-87, 2001, doi: 10.1108/01443570110358468.

[9] P. Akhtar, "Determinants of Coordination Effectivess of Selected International Agri-Food Supply Chains: A Structural Equation Modelling Approach," Massy University, 2013.

[10] A. Singh, "Improving Efficiency and Reducing waste for Sustainable Beef Supply Chain," Norwich Business School, 2018.

[11] S. Prakash, G. Soni, A. P. S. Rathore, and S. Singh, "Risk analysis and mitigation for perishable food supply chain: a case of dairy industry," Benchmarking An Int. J., vol. 24, no. 1, pp. 2-23, 2017, doi: 10.1108/BIJ-072015-0070.

[12] Selim Jahan, “Human Development Report 2016,” 2016. doi: eISBN: 978-921-060036-1.

[13] European Environment Agency (EEA), "Economy and Development," 2019. doi: 10.1017/CBO9781107415324.004.

[14] World Bank, "Prospects for Growth and Jobs in the Palestinian Economy A General Equilibrium Analysis," 2017.

[15] Y. YADAV, G. YADAV, and S. CHAUHAN, "IMPLEMENTATION OF 5 S IN $B A N K S$," in International Journal of Research in Commerce, Economics and Management, 2011, vol. 1, no. 2, doi: 10.1017/CBO9781107415324.004.

[16] S. hossein Nikou and H. Selamat, "Risk Management Capability within Malaysian Food Supply Chains," Int. J. Agric. Econ. Dev., vol. 1, no. 1, pp. 37-54, 2013.

[17] World Economic Forum, "Global Risks 2010: A Global Risk Network Report," 2010. [Online]. Available: https://www.weforum.org/reports/globalrisks-2010.

[18] M. S. Shahbaz, A. B. Soomro, S. Soomro, S. Sohu, and B. Ahmed, "The Role of Supply Chain Relationships in Risk Management by Enhancing Customer Satisfaction," Int. J. Disaster Recover. Bus. Contin., vol. 11, no. 1, pp. 17561765, 2020.

[19] D. L. Olson and D. Wu, "Risk management models for supply chain: a scenario analysis of outsourcing to China," Supply Chain Manag. An Int. J., vol. 16, no. 6, pp. 401-408, 2011, doi: 10.1108/13598541111171110.

[20] M. S. Shahbaz, B. A. Othman, P. M. Salman, D. A. Memon, and R. Z. B. R. Rasi, "A Proposed Conceptual Action Plan for Identification, Assessment and Mitigation of Supply Chain Risks," Int. J. Adv. Oper. Manag., vol. 12, no. 1, pp. 65-80, 2020.

[21] M. S. Shahbaz, M. S. Mubarik, M. F. Mubarak, and M. B. Irshad, "The Impact of Lean Practices on Educational Performance: An Empirical Investigation for Public Sector Universities of Malaysia," J. Indep. Stud. Res. Soc. Sci. Econ., vol. 17, no. 2, pp. 85-96, 2019. 
[22] J. F. Hair, M. Sarstedt, C. M. Ringle, and J. F. Hair, "Rethinking some of the rethinking of partial least squares Rethinking some of the rethinking of partial least squares," 2019, doi: 10.1108/EJM-10-2018-0665.

[23] M. S. Shahbaz, F. A. Shaikh, M. A. Qureshi, Q. B. Jamali, and S. Sohu, "The Influence of Supply Chain Collaboration on Supply Chain Performance for Malaysian Manufacturing Industry," J. Organ. Behav. Res., vol. 4, no. 2, pp. 203-218, 2019.

[24] M. S. Shahbaz, R. Z. R. Rasi, and M. F. Bin Ahmad, "A Novel Classification of Supply Chain Risks: Scale Development and Validation," J. Ind. Eng. Manag., vol. 12, no. 1, pp. 201-218, 2019, doi: http://dx.doi.org/10.3926/jiem.2792. 